\title{
ASSOCIAÇÃO ENTRE AS ALTERAÇÕES DE ALIMENTAÇÃO INFANTIL E DISTÚRBIOS DE FALA E LINGUAGEM
}

\section{Association between speech/language and feeding disorders in children}

\author{
Beatriz Helena Vieira Maranghetti Ferriolli ${ }^{(1)}$
}

\begin{abstract}
RESUMO
Objetivo: verificar a associação entre distúrbios de alimentação infantil e as alterações de fala e linguagem. Dessa forma, buscou-se caracterizar o tipo de transtorno em associação com o desempenho de fala e linguagem da criança, assim como o tipo de interação que as mães mantêm com seus filhos. Métodos: os sujeitos dessa pesquisa foram 24 crianças, na faixa etária entre um e oito anos, com diagnóstico de transtorno alimentar e suas mães. As crianças foram filmadas em situação de alimentação e avaliadas em relação à sua fala e linguagem. As mães foram entrevistadas sobre a atitude que mantêm com os filhos no que se refere à alimentação. Resultados: das crianças pesquisadas, $46 \%$ apresentaram alteração na fala, $25 \%$ na fala e linguagem e $29 \%$ sem alterações. Portanto, $71 \%$ das crianças apresentaram algum tipo de alteração na aquisição ou produção do sistema fonético-fonológico e/ou na linguagem. Conclusões: foi possível identificar uma estreita relação entre transtornos de alimentação e hábitos parafuncionais o que facilita a instalação de um distúrbio articulatório, principalmente com alteração nos fonemas linguodentais e dento-alveolares. Quanto à linguagem, as crianças apresentaram uma defasagem em torno de um ano em relação à mesma faixa etária.
\end{abstract}

DESCRITORES: Fala, Linguagem, Comportamento Alimentar, Criança.

\section{INTRODUÇÃO}

O alimento além de representar a possibilidade de crescimento e desenvolvimento de um organismo, relaciona-se com aspectos sociais e interativos do sujeito, pois a refeição torna-se um ritual onde as pessoas podem se encontrar e manifestar trocas interativas, principalmente entre as mães e seus filhos ${ }^{1}$.

A criança, quando pequena, encontra-se em uma situação de extrema dependência em relação ao adulto que o alimenta, no entanto, segundo Brazelton todo recém-nascido estabelece, desde cedo, uma relação que chamaríamos de "mão dupla" já que dialoga com seu meio ambiente da mesma forma que sofre suas influências².

Nesse sentido, a criança não tem um papel passivo na díade (bebê-adulto), o que confirma achados

\footnotetext{
(1) Fonoaudióloga; Professora Doutora dos Cursos de Pósgraduação em Fonoaudiologia e Letras da Universidade de Ribeirão Preto, UNAERP. Pós-doutora pela Faculdade de Medicina da USP de Ribeirão Preto.

Conflito de interesses: inexistente
}

relacionados aos estudos sociointeracionistas mais recentes, os quais têm demonstrado que a criança apresenta uma intenção comunicativa desde muito cedo em sua vida ${ }^{3}$.

O contato precoce e intenso entre a mãe e o bebê, logo após o nascimento, terá uma representação psíquica e emocional que repercutirá no futuro da criança. Os gestos, carinhos e conversas da mãe com o seu bebê tranqüilizam a criança e lhe dão segurança. Alterações no relacionamento mãefilho durante a primeira infância trarão seqüelas à criança que poderão perdurar por toda a vida ${ }^{1-2}$.

Um dos transtornos que podem aparecer na primeira infância é o de alimentação. De acordo com o critério da DSM - IV, o transtorno de Alimentação da Primeira Infância diz respeito a uma falha persistente em comer ou mamar adequadamente. Tal transtorno se reflete como um fracasso significativo para ganhar peso ou uma perda de peso significativa ao longo de pelo menos um mês. A obesidade simples é incluída na Classificação Internacional das Doenças (CID - 10) como uma condição médica geral ${ }^{4}$. 
As questões relacionadas aos transtornos de alimentação infantil, incluindo a obesidade, são abrangentes e exigem um trabalho multidisciplinar ${ }^{5}$. Com frequência, bebês com transtornos de alimentação demonstram irritabilidade principalmente durante o momento de alimentação, em contrapartida, poderão apresentar um comportamento de apatia e serem retraídos, apresentando atrasos no desenvolvimento. Podem surgir problemas de interação entre a mãe e a criança desencadeados por reações agressivas dos pais diante da recusa alimentar do bebê ${ }^{6}$.

Ferriolli ${ }^{7-10}$ constatou que a maneira como os pais interagem com seus filhos pode ser fator desencadeante e persistente de um retardo de linguagem, pois a gênese desse atraso pode anteceder seu surgimento, ou seja, antes mesmo da criança manifestar a alteração na fala ou na estrutura linguística de seu discurso ela já é falada como alguém que possui um problema ou que não é capaz de desenvolver adequadamente sua linguagem.

Verifica-se que as pesquisas fonoaudiológicas ligadas aos transtornos alimentares têm se voltado, em especial, para os quadros de disfagias ${ }^{11}$, não abrangendo, no entanto, estudos que correlacionem aspectos de fala e interativos entre a mãe e a criança. Da mesma forma, outros transtornos, ligados à alimentação, tais como repulsa ao alimento, vômitos constantes e anorexia secundária não têm sido igualmente pesquisados.

Felício et al. realizaram um trabalho com crianças da pré-escola correlacionando as condições miofuncionais à fala, concluindo que a sucção prolongada pode vir a modificar o espaço oral, dificultando a fala ${ }^{12}$.

O objetivo dessa pesquisa foi verificar se existe uma associação entre os transtornos de alimentação infantil e as alterações de fala e linguagem, assim como, em que medida a interação entre a mãe e a criança interfere na presença do distúrbio de alimentação e/ou de fala e linguagem.

\section{MÉTODOS}

O estudo foi observacional transversal. Foram selecionadas 24 crianças entre um ano e oito anos dos Centros de Saúde Escola vinculados à Faculdade de Medicina da USP de Ribeirão Preto, todas elas possuíam diagnóstico de transtorno de alimentação. Esta faixa etária abrange crianças que estão em fase inicial de aquisição de linguagem e aquelas que, pela cronologia normal de aquisição de linguagem e processos fonológicos, já deveriam ter desenvolvido sua fala e linguagem. Não foram avaliadas crianças com sequelas neurológicas, síndromes, déficit mental ou deficiência auditiva. O nível sócio-econômico e cultural das famílias não foi critério de exclusão e nem de seleção, no entanto em função do local de coleta, as famílias pertencem a uma população sócio-econômica e cultural menos favorecida.

As avaliações foram realizadas na própria residência das crianças para que fosse conservado tanto o tipo de alimento oferecido como os instrumentos utilizados na alimentação, o local onde a criança faz suas refeições e o comportamento da mãe e/ou cuidador. O horário de visita foi o mais favorável para a família e que estivesse de acordo com as propostas do trabalho (almoço ou jantar). A pesquisadora levou brinquedos e livros de história para motivar a fala e linguagem das crianças através do lúdico. A duração foi em média de 90 minutos para cada criança.

Foi aplicado um roteiro de observação das filmagens baseado no Protocolo de Observação Comportamental (PROC) ${ }^{14}$ para avaliação do desenvolvimento comunicativo e cognitivo infantil, um questionário semi-estruturado e protocolos de registro sobre a alimentação e tipo de distúrbio alimentar que a criança apresenta e avaliação da fala e linguagem das crianças. Foi utilizado o ABFW ${ }^{15}$ nas áreas de Fonologia e Vocabulário.

Houve preferência pelo termo 'alteração' de fala e/ou linguagem e não 'distúrbio' porque na faixa etária dos primeiros dois primeiros anos da criança não se consideram as alterações como sendo um distúrbio, uma vez que a criança tem plena condição de atingir uma normalidade tanto em termos de repertório fonético fonológico como de sua linguagem (PROC) ${ }^{14}$

A pesquisa foi aprovada pelo Comitê de Ética em Pesquisa do Hospital das Clínicas de Ribeirão Preto de acordo com o Processo HCRP no 4254/2005, sendo realizada após a assinatura, pelos pais, do Termo de Consentimento Livre e Esclarecido.

Os resultados foram analisados qualitativamente, não foi utilizada nenhuma análise estatística por não haver número suficiente de sujeitos e não ser esse o objetivo do estudo.

\section{RESULTADOS}

Os dados obtidos nesse estudo são muito extensos. Sendo assim, foram privilegiados os resultados que associem os transtornos alimentares e as alterações de fala e linguagem.

Todas as crianças selecionadas já possuíam um diagnóstico de transtorno de alimentação, constatado através dos prontuários. Participaram da pesquisa respondendo a um questionário semiestruturado 24 mães e um pai, pois em uma das residências o pai estava presente e foi possível 
avaliar, inclusive, sua interação com o filho. Acredita-se que o discurso dos pais, no momento de uma entrevista, passa de dados informativos sobre as etapas de desenvolvimento do filho para indícios linguístico-discursivos que direcionam para a compreensão do sintoma referido ${ }^{7-9,16}$.

Os dados foram analisados comparando 0 tipo de transtorno alimentar e a presença ou não de alterações na fala e/ou linguagem, os hábitos deletérios, como a sucção nutritiva (SN) e não- nutritiva (SNN) foram considerados na discussão devido a sua importante associação com os desvios de fala.

Optou-se, em um primeiro momento, por descrever todos os sujeitos através de duas tabelas, a primeira traz uma idéia geral dos sujeitos considerando-se a idade, sexo e a queixa manifesta pela mãe. Já na segunda, foi descrito o tempo de amamentação e se a criança fez uso de mamadeira e/ ou chupeta e o tempo de hábito.

Tabela 1 - Representa os sujeitos avaliados comparando idade, sexo e tipo de transtorno alimentar

\begin{tabular}{|c|c|c|c|}
\hline SUJEITOS & IDADE & SEXO & DIAGNÓSTICO \\
\hline 1 & 12 meses & feminino & baixo peso \\
\hline 2 & 1ano e 3 meses & feminino & inapetência \\
\hline 3 & 1 ano e 11 meses & masculino & baixo peso \\
\hline 4 & 2 anos & masculino & inapetência \\
\hline 5 & 2 anos e 5 meses & masculino & baixo peso \\
\hline 6 & 2 anos e 10 meses & masculino & inapetência \\
\hline 7 & 3 anos & feminino & inapetência \\
\hline 8 & 3 anos e 6 meses & feminino & inapetência \\
\hline 9 & 3 anos e 6 meses & masculino & inapetência \\
\hline 10 & 4 anos & masculino & desnutrição \\
\hline 11 & 4 anos e 3 meses & feminino & inapetência \\
\hline 12 & 4 anos e 7 meses & feminino & obesidade \\
\hline 13 & 5 anos e 2 meses & feminino & sobrepeso \\
\hline 14 & 5 anos e 2 meses & masculino & obesidade e vômito \\
\hline 15 & 5 anos e 6 meses & masculino & refluxo \\
\hline 16 & 6 anos e 1 mês & masculino & obesidade e problemas de fala \\
\hline 17 & 6 anos e 3 meses & masculino & sobrepeso e problemas de fala \\
\hline 18 & 6 anos e 10 meses & masculino & obesidade \\
\hline 19 & 7 anos e 8 meses & feminino & inapetência \\
\hline 20 & 7 anos e 9 meses & masculino & sobrepeso \\
\hline 21 & 7 anos e 11 meses & masculino & sobrepeso \\
\hline 22 & 8 anos e 4 meses & masculino & sobrepeso e problemas de fala \\
\hline 23 & 8 anos e 6 meses & masculino & sobrepeso e problemas de fala \\
\hline 24 & 8 anos e 11 meses & feminino & obesidade \\
\hline
\end{tabular}

Foram registradas as seguintes queixas de transtornos de alimentação infantil, de acordo com a Tabela 1:

- Quadro de desnutrição: uma criança;

- Refluxo gastroesofágico (RGE): uma criança;

- Baixo Peso: três crianças;

- Obesidade: cinco crianças;

- Sobrepeso: seis crianças;

- Inapetência: oito crianças.

Conforme a Tabela 2, 46\% das crianças com alteração na fala, $25 \%$ na fala e linguagem e $29 \%$ sem alterações. Portanto, $71 \%$ das crianças avaliadas apresentaram algum tipo de alteração na aquisição ou produção do sistema fonético- fonológica e/ou na linguagem.

\section{DISCUSSÃO}

$\mathrm{Na}$ amostra avaliada constatou-se uma alta incidência de alterações de fala e linguagem (71\%). Dos sete sujeitos que não apresentaram problemas com a fala, somente um deles não possui nenhuma alteração morfofuncional dos órgãos fonoarticulatórios. 
Tabela 2 - Relação entre o tipo de transtorno de alimentação infantil, o tempo de amamentação, os hábitos deletérios ligados ao uso prolongado de mamadeira e/ou chupeta e a presença de alteração de fala e linguagem

\begin{tabular}{|c|c|c|c|c|}
\hline SUJEITOS & $\begin{array}{l}\text { TEMPO DE } \\
\text { AMAMENTAÇÃO } \\
\text { NO PEITO }\end{array}$ & $\begin{array}{l}\text { TEMPO DE USO DA } \\
\text { MAMADEIRA }\end{array}$ & $\begin{array}{c}\text { TEMPO DE USO DE } \\
\text { CHUPETA }\end{array}$ & $\begin{array}{c}\text { ALTERAÇÃO DE FALA } \\
\text { (AF) E/OU DE } \\
\text { LINGUAGEM (AL) OU } \\
\text { SEM ALTERAÇÕES (SA) }\end{array}$ \\
\hline $\begin{array}{c}1 \\
\text { baixo peso }\end{array}$ & $\begin{array}{c}\text { com } 12 \text { meses ainda } \\
\text { é amamentada }\end{array}$ & Faz uso & Faz uso & $\mathrm{AF}+\mathrm{AL}$ \\
\hline $\begin{array}{c}2 \\
\text { inapetência }\end{array}$ & $\begin{array}{l}\text { com } 15 \text { meses ainda } \\
\text { é amamentada }\end{array}$ & Faz uso & Faz uso & $\mathrm{AF}+\mathrm{AL}$ \\
\hline $\begin{array}{c}3 \\
\text { baixo peso }\end{array}$ & um mês & Faz uso & Faz uso & SA \\
\hline $\begin{array}{c}4 \\
\text { inapetência }\end{array}$ & uma semana & Faz uso & Faz uso & $A F+A L$ \\
\hline $\begin{array}{c}5 \\
\text { baixo peso }\end{array}$ & $\begin{array}{c}\text { com } 2 \text { anos e } 5 \\
\text { meses ainda é } \\
\text { amamentada }\end{array}$ & Faz uso & Faz uso & SA \\
\hline $\begin{array}{c}6 \\
\text { inapetência }\end{array}$ & não foi amamentada & Faz uso & Faz uso & $A F+A L$ \\
\hline $\begin{array}{c}7 \\
\text { inapetência }\end{array}$ & 4 meses & Faz uso & Não usou & $\mathrm{AF}$ \\
\hline $\begin{array}{c}8 \\
\text { inapetência }\end{array}$ & 6 meses & Faz uso & Não usou & $\mathrm{AF}$ \\
\hline $\begin{array}{c}9 \\
\text { inapetência }\end{array}$ & 4 meses & Faz uso & Faz uso & $A F+A L$ \\
\hline $\begin{array}{c}10 \\
\text { desnutrição }\end{array}$ & não foi amamentada & Faz uso & Não usou & $A F+A L$ \\
\hline $\begin{array}{c}11 \\
\text { inapetência }\end{array}$ & 15 dias & Faz uso & Faz uso & $\mathrm{AF}$ \\
\hline $\begin{array}{c}12 \\
\text { obesidade }\end{array}$ & não foi amamentada & Faz uso & Não usou & SA \\
\hline $\begin{array}{c}13 \\
\text { sobrepeso }\end{array}$ & 3 meses & Faz uso & Não usou & $\mathrm{AF}$ \\
\hline $\begin{array}{c}14 \\
\text { obesidade e vômito }\end{array}$ & 3 meses & Faz uso & Não usou & SA \\
\hline $\begin{array}{c}15 \\
\mathrm{RGE}\end{array}$ & 6 meses & Até 4 anos & Não usou & $\mathrm{AF}$ \\
\hline $\begin{array}{c}16 \\
\text { Obesidade e } \\
\text { problema de fala }\end{array}$ & não foi amamentada & Faz uso & Não usou & AF \\
\hline $\begin{array}{c}17 \\
\text { sobrepeso e } \\
\text { problema de fala }\end{array}$ & 3 meses & Faz uso & Não usou & $\mathrm{AF}$ \\
\hline $\begin{array}{c}18 \\
\text { obesidade }\end{array}$ & 4 meses & Até 5 anos & Não usou & SA \\
\hline $\begin{array}{c}19 \\
\text { inapetência }\end{array}$ & 3 meses & Faz uso & Usou até os 5 anos & SA \\
\hline $\begin{array}{c}20 \\
\text { sobrepeso }\end{array}$ & não foi amamentada & Até 4 anos & Não usou & $\mathrm{AF}$ \\
\hline $\begin{array}{c}21 \\
\text { sobrepeso }\end{array}$ & 3 meses & Até 3 anos & Não usou & $\mathrm{AF}$ \\
\hline $\begin{array}{c}22 \\
\text { sobrepeso e } \\
\text { problemas de fala }\end{array}$ & não foi amamentada & Até 5 anos & Não usou & AF \\
\hline $\begin{array}{c}23 \\
\text { sobrepeso }\end{array}$ & 1 ano e 2 meses & Até 5 anos & Usou até 4 anos & SA \\
\hline $\begin{array}{c}24 \\
\text { obesidade }\end{array}$ & 4 meses & Faz uso & Não usou & AF \\
\hline
\end{tabular}


Tal incidência, provavelmente, está relacionada à manutenção dos hábitos de sucção da mamadeira e/ou chupeta quando esta se prolonga além dos três anos e meio de idade. Devido à força mecânica exercida pelos bicos artificiais, vários autores concordam que os hábitos de sucção prolongados são fatores etiológicos de maloclusões ${ }^{17-19}$.

Até os 18 meses de vida o tipo de aleitamento não produz diferenças significativas na estrutura anatômica da cavidade oral, no entanto, após essa idade poderão ocorrer alterações nas medidas de maxila e mandíbula que desestabilizarão as relações de oclusão ${ }^{20}$. Robbins e Klee ${ }^{21}$ descreveram a importância entre a integração dos sistemas motor, sensório e auditivo com o crescimento musculoesquelético e maturação neural nos primeiros 24 meses de vida.

Em estudo recente, Felício et al. ${ }^{12}$ associaram o distúrbio de fala em crianças com faixa etária média de 6,5 anos de idade, com a maior duração do aleitamento artificial e sucção não-nutritiva. No presente estudo pode-se confirmar tais achados, uma vez que das 15 crianças com faixa etária acima dos três anos e meio que deveriam ter deixado o hábito de sucção com mamadeira, somente uma deixou de mamar aos três anos, ou seja 93\% fizeram ou fazem uso de mamadeira. Dessas crianças, aquelas que não possuem alteração na fala apresentam alteração estrutural e/ou funcional relacionadas aos órgãos fonoarticulatórios.

Verificou-se, com este estudo, um alto número de crianças que não foram amamentadas no peito ou que mamaram até, no máximo, os quatro meses. Sabe-se que a sucção no peito é um estímulo importante para o crescimento ósseo e desenvolvimento das funções orais. No entanto, o que ficou constado é que cada vez mais há substituição do peito pelo bico artificial, em função das exigências da vida moderna, uma vez que as mulheres possuem ocupações fora de seus lares. Outro complicador é o momento da retirada da mamadeira, sendo que o mais comum é as mães terem uma tolerância grande em relação a esse aspecto porque sentem pena da criança ficar sem mamar ou ficam preocupadas com a diminuição no consumo do leite ${ }^{22-24}$.

Um estudo realizado por Czlusniak et al. ${ }^{25}$ objetivou identificar a incidência de alterações de motricidade orofacial e hábitos nocivos em crianças entre cinco e sete anos. Constataram que 24 de 31 crianças apresentavam tais alterações. Cozza et al. ${ }^{26}$ também identificaram que os hábitos prolongados de sucção são fatores de riscos significantes para a instalação da mordida aberta anterior ${ }^{24}$

Serra-Negra et al. ${ }^{27}$ confirmaram a repetição pelos filhos dos hábitos bucais das mães. A maioria das mães pesquisadas (72\%) tinha consciência do prejuízo que os hábitos poderiam causar nos filhos. Nesse estudo foi possível ouvir as mães com relação ao uso prolongado da mamadeira e todas foram unânimes em afirmar que têm medo em tirar a mamadeira porque a criança deixará de tomar leite, na maioria das vezes a mãe nem tenta fazer a troca pelo copo.

Os tipos de alterações encontradas na fala dos sujeitos foram distúrbios articulatórios, ou seja, desvios fonéticos que atingem em especial os fonemas fricativos e oclusivos linguodentais /s/, /z/ e /t/ e /d/, respectivamente. Esse fato é totalmente compatível com a projeção da língua devido aos hábitos deletérios e relaxamento desse músculo, pois todos os sujeitos com presença do distúrbio articulatório apresentavam uma deglutição atípica (48,5\%).

Foi realizada uma pesquisa bibliográfica relacionada às áreas de Pediatria, Odontologia e Fonoaudiologia e constataram que o desmame precoce pode levar à ruptura do desenvolvimento adequado do sistema motor oral prejudicando as funções de mastigação, deglutição, respiração e articulação dos fonemas, além de acarretar má oclusão e respiração predominantemente oral ${ }^{28}$.

As alterações de linguagem nos sujeitos pesquisados, de acordo com as observações realizadas, referem-se a pouca iniciativa do adulto no ato comunicativo tanto em iniciar turnos discursivos como em "espelhar" e complementar o parceiro dialógico. As crianças desse grupo encontravam-se na faixa etária entre um ano e quatro anos de idade todos com transtornos alimentares de baixo peso ou inapetência.

Estudos recentes mostram que crianças prematuras constituem um grupo de risco para problemas cognitivos, comportamentais e dificuldades de aprendizagem, podendo apresentar atrasos e desvios na fala e linguagem e necessitando dos cuidados de uma equipe multidisciplinar ${ }^{29}$.

Identificou-se, nos sujeitos estudados, que somente um deles foi prematuro, os demais nasceram a termo e saudáveis, sendo que a deficiência de nutrientes veio posteriormente, muito provavelmente em função da carência sócio-econômica e cultural do grupo estudado. Outro aspecto importante de ser ressaltado é que várias mães mantêm a mamadeira além do que seria necessário e saudável para a criança, pois elas ganham de algumas creches o leite em pó e usam o leite como principal fonte de alimentação em uma fase da vida da criança que ela deveria se alimentar com frutas, vegetais, legumes e outras proteínas. Para tanto, as mães teriam que cozinhar e, muitas delas não se dispõem a esta tarefa.

Atrasos na linguagem da criança encontramse, muitas vezes, relacionados ao tipo de discurso 
que os pais mantêm com seus filhos, julgando-os incapazes para um bom desempenho de fala e linguagem ${ }^{7-9}$. Em estudo anterior ficou constatado, através do discurso de pais, que, inconscientemente, eles queriam manter seus filhos como bebês ou associavam a dificuldade de fala e linguagem a uma doença crônica. A partir de uma concepção mais ampla de sujeito, na clínica fonoaudiológica, cabe aos profissionais dessa área investigar outros fatores que possam estar correlacionados ou interferindo na evolução do quadro, podendo, a partir dessa postura, encontrar meios mais eficazes de lidar com situações mais crônicas e persistentes.

Seis sujeitos (25\%) que se encontravam na faixa etária até os quatro anos apresentaram alteração na aquisição e desenvolvimento da fala e linguagem de acordo com o PROC ${ }^{14}$ e teste de vocabulário do $\mathrm{ABFW}{ }^{15}$. As mães foram observadas em interação com seus filhos e pudemos constatar antecipação da mãe em relação às ações e às respostas que a criança deveria emitir. Ficou evidente uma assimetria dialógica com predomínio da fala da mãe e antecipação de ações no sentido de escolher o brinquedo e definir a brincadeira.

Estudos demonstraram que a criança deve ser significada e representada pelo outro desde muito cedo ${ }^{3,7,8}$. De acordo com os registros realizados durante essa pesquisa foi possível constatar que as mães dificilmente interagiam com seus filhos e os representavam como interlocutores com potencial discursivo. Provavelmente vários fatores encontram na gênese das dificuldades de interação, tais como: pai e mãe pouco afetuosos, a representação que os pais fazem de seus filhos, dentre outros.

Toda criança necessita ter um interlocutor que o represente em termos discursivos, aquele que a significará como alguém que possui potencial para "conversar" e interagir. Relacionado a tal aspecto, dois casos merecem destaque na pesquisa realizada e serão relatados na seguência.

O primeiro deles, diz respeito a uma mãe que estava aparentemente "drogada" e que as condições da casa e das crianças (quatro filhos) mostravam-se precárias pela sua higiene. Apesar disso a criança de dois anos e cinco meses apresentou um desenvolvimento adequado de fala e linguagem para sua faixa etária, provavelmente estimulada pelos outros irmãos mais velhos que pareciam assumir o papel de interlocutores da criança.

O segundo caso refere-se a uma mãe com quadro severo de depressão e que relatou não ter a mínima condição de criar o filho de um ano e 11 meses. No entanto, o pai estava presente na casa e interagiu o tempo todo com o filho, conversando com ele, dando-lhe colo e o alimentando.

Frequentemente encontram-se pais sem paciência para ouvir os filhos e incapazes de significar os enunciados emitidos pelas crianças, o que dificulta a interação entre os mesmos. Tal fato, pode acarretar um atraso no desenvolvimento lingüístico dos infantes e, no caso dos sujeitos desse estudo, poderão ser agravados pela ansiedade dos pais ${ }^{30} \mathrm{em}$ função do transtorno de alimentação que os filhos apresentam. Algumas mães relataram sentirem-se ansiosas e culpadas pelo estado de "desnutrição" dos filhos.

Um estudo bastante interessante comparou a percepção materna e a autopercepção das crianças com relação ao seu estado nutricional e foram detectados erros em relação à representação adequada do peso entre as crianças e suas mães. Em especial quando havia excesso de peso, este não era reconhecido pela mãe e pelas crianças, o que pode significar um obstáculo no correto reconhecimento das alterações nutricionais e, consequentemente em seu tratamento ${ }^{31}$. Esse pode vir a ser um aspecto prejudicial quando se trata da mãe ser a principal colaboradora na reformulação e acompanhamento das dietas de seus filhos.

A maior parte dos sujeitos estudados pertence a uma população de baixa renda e apesar de muitas crianças apresentarem desnutrição ou baixo peso as mães eram obesas. Esse seria um outro tema interessante para estudo.

\section{CONCLUSÃO}

Nossa proposta foi verificar a ocorrência ou não de uma associação entre os transtornos de alimentação infantil e as alterações de fala e linguagem. Com base nos resultados, foi possível concluir que houve uma alta incidência dessas alterações, em especial o distúrbio articulatório.

Os hábitos deletérios persistiam na maioria das crianças acarretando um comprometimento na estrutura anatomofuncional dos órgãos fonoarticulatórios colaborando para as alterações de fala, afetando, em especial, a produção dos fonemas linguodentais e dento-alveolares.

No que se refere à aquisição e desenvolvimento da linguagem, as crianças mais novas, até os quatro anos, demonstraram ter um repertório abaixo do que seria esperado na mesma faixa etária, tanto em relação ao léxico, como à estrutura de frase e estratégias comunicativa interativas.

Os transtornos de alimentação infantil investigados: baixo-peso, inapetência, refluxo e obesidade demonstraram ter uma associação com alterações da fala e linguagem. No entanto, fica aqui sugerido um estudo mais abrangente quanto à diversidade da população estudada no que diz respeito às características sócio econômica e cultural e à faixa etária, além de um número maior de sujeitos. 


\begin{abstract}
Purpose: to check the connection between feeding disorders and speech language disorders in children. Thus, we tried to characterize the type of disorder in association with the child's speech and language performance, as well as the kind of interaction among mothers and their children. MethodS: the subjects in this research were 24 children (between one and eight year old) diagnosed with feeding disorders, and their mothers. Children were video-recorded while eating and were also evaluated in regard to their speech and language status. Mothers were interviewed about their attitude towards children concerning eating habits. Results: out of the researched children, $46 \%$ manifested speech disturbs, $25 \%$ had speech and language disorders and $29 \%$ showed no changes. Therefore, $71 \%$ of those children proved to have some sort of alteration in phonological acquisition or production and/ or in language. Conclusions: it was possible to identify a close relation among feeding disorders and parafunctional habits, which makes easy for an articulation disorder to take place, mainly with a change in tongue-tip and teeth-ridge phonemes. As for the language, the children showed a language delay of around one year when compared to those of the same age group.
\end{abstract}

KEYWORDS: Speech; Language; Feeding Behavior; Children

\section{REFERÊNCIAS}

1. Rotenberg S, De Vargas S. Nutrition habits and healthcare: feeding the children and the family. Rev. Bras. Saude Mater. Infant. 2004; 4(1):85-94.

2. Brazelton TB. Bebês e mamães. Rio de Janeiro: Campus; 1981.

3. Lemos C. Das vicissitudes da fala da criança e de sua investigação. Cad Estud Linguíst. 2002; 42:41-69.

4. Classificação Estatística Internacional de Doenças e Problemas Relacionados à Saúde. [homepage na internet] CID 10, 1993. [atualizada em 2008; acesso em 24 de outubro de 2009] Disponível em www. datasus.gov.br/cid10/webhelp/cid10.htm.

5. De Almeida CCJN, Barreto RF, Oliveira VA, Ferriolli BHVM, João $C A$, João $C R$, Ricco RC, Ramos APP, Almeida CAN. Atuação interdisciplinar em obesidade infanto-juvenil: a experiência do CESNI. Ver de Nutrologia. 2008; 1(1):28-34.

6. Balaban G, Silva GAP. Efeito protetor do aleitamento materno contra a obesidade infantil. J Pediatr. 2004; 80(1):7-16.

7. Ferriolli BHVM. Como as crianças com retardo de linguagem são representadas no discurso familiar. [dissertação] Ribeirão Preto (SP): Universidade de São Paulo; 2000. 202p.

8. Tfouni LV, Ferriolli BHVM. O retardo de linguagem como resultado do discurso dos pais. In: Del Ré A, Fernandes SD (org.).A linguagem da criança: sentido, corpo e discurso. São Paulo: Cultura Acadêmica; 2008. p. 165-80.

9. Tfouni L, Ferriolli BHVM, Moraes J. A concepção de sujeito na clínica fonoaudiológica: a proposta de um novo paradigma. Pró-Fono. 2002; 14(2):275-82.
10. Ferriolli BHVM. Objeto do desejo: a manifestação metafórica e metonímica no retardo de linguagem. [tese] Ribeirão Preto (SP): Universidade de São Paulo; 2003. 209p.

11. Levy DS, Rainho L. Abordagem em disfagia infantil - proposta fonoaudiológica e fisioterápica. In: Jacobi JS, Levy DS, Silva LMC. Disfagia: avaliação e tratamento. Rio de Janeiro: Revinter; 2003. p.37-65.

12. Felício CM, Ferreira-Jerônimo R, Ferriolli BHVM, Freitas RLRG. Análise da Associação entre sucção, condições miofuncionais orais e fala. Pró-Fono. 2003; 15(1):31-40.

13. Parizzi MR, Tassara V. Obesidade na infância. In: Fonseca JGM, Souza e Silva MK, organizadores. Obesidade e outros distúrbios alimentares. São Paulo: MEDSI; 2001. p. 279-89.

14. Zorzi JL, Hage SRV. PROC - Protocolo de observação comportamental. São José dos Campos: Pulso; 2004.

15. Andrade CRF, Befi-Lopes DM, Fernandes FDM, Wertzner HF. ABFW - Teste de Linguagem infantil: nas áreas de fonologia, vocabulário, fluência e pragmática. Carapicuíba: Pró-Fono; 2000.

16. Sobrinho A. Dizer o dito: a questão da interpretação na fonoaudiologia. Rev Dist Comun. 1996; 8(1):23-39.

17. Scavone-Junior H , Ferreira RI, Mendes TE, Ferreira FV. Prevalence of posterior crossbite among pacifier users: a study in the deciduous dentition. Braz. Oral res. 2007; 21 (2): 153-8.

18. Thomaz EBAF, Valença AMG. Relationship between childhood underweight and dental crowding in deciduous teething. J. Pediatr. 2009; 85(2):110-6. 
19. Serra Negra JMC, Pordeus IA, Rocha Junior JE. Estudo da associação entre aleitamento, hábitos bucais e maloclusão. Rev Odontol USP. 1997; 11:79-86.

20. Heimer MV, Katz CRT, Rosenblatt A. Nonnutritive sucking habits, dental malocclusions, and facial morphology in Brazilian children: a longitudinal study. European Journal of orthodontics. 2008; 30(6) 580-5.

21. Robbins J, Klee T. Clinical assessment of oropharingeal motor development in young children. J Speech Hear Disord. 1987; 52(3):271-7.

22. Souza FRN, Taveira, GS, Almeida RVD, Padilla WWN. O aleitamento materno e sua relação com hábitos deletéreos e maloclusão dentária. Pesq Bras Odontoped Clin Integr. 2004; 4(3):211-6.

23. Souza DFRK, Valle MAS, Pacheco MCT. Relação clínica entre hábitos de sucçlão, má oclusão, aleitamento e grau de informação prévia das mães. Dent Press Ortodon Ortop Facial. 2006; 11(6):81-90.

24. Araújo CMT, Silva GAP, Coutinho SB. Aleitamento materno e uso de chupeta: repercussões na alimentação e no desenvolvimento do sistema motor oral. Rev Paul Pediatr. 2007; 25(1):59-65.

25. Czlusniak GR, Carvalho FC, Oliveira JP. Alterações de motricidade orofacial e presença de hábitos nocivos orais em crianças de 5 a 7 anos de idade: implicações para intervenções fonoaudiológicas em âmbito escolar. Publ. UEPG Ci. Biol. Saúde. Ponta Grossa. 2008; 14(1):29-39.

26. Cozza P, Baccetti T, Franchi L, Mucedero M, Polimeri A. Sucking habits and facial hyperdivergency as risk factors for anterior open bite in the mixed dentition. Am J Orthod Dentofac Orthop. 2005; 128(4):517-9.

27. Serra Negra JMC, Camargo VL, Robert RA, Pinto AELS, Martins OS, Almeida PI. Hábitos bucais deletérios: os filhos que imitam as mães na adoção destes hábitos? Rev Odonto Ciênci. 2006; 21(52):146-52.

28. Neiva FCB, Cattoni DM, Ramos JLA, Issler $\mathrm{H}$. Desmame precoce: implicações para o desenvolvimento motor-oral. J Pediatr. 2003; 79(1):7-12.

29. Lamônica DAC, Picolini MM. Habilidades do desenvolvimento de prematuros. Rev CEFAC. 2009; 11(2):145-53.

30. Esparó G, Canal J, Jané C, Ballespi S, Viñas F, Domenéch $E$. Feeding problems in nursey children: prevalence and psychosocial factors. Acta Paediatr. 2004; 93:663-8.

31. Boa-Sorte N, Neri LA, Leite MEQ, Brito SM, Meirelles AR, Luduvice FBS, et al. Percepção materna e autopercepção do estado nutricional de crianças e adolescentes de escolas privadas. J.Pediatr. 2007; 83(4):349-56.

DOI: 10.1590/S1516-18462010005000037

RECEBIDO EM: 18/08/2009

ACEITO EM: 18/02/2010

Endereço para correspondência:

Beatriz Ferriolli

Av: Senador César Vergueiro, 1155

Ribeirão Preto - SP

CEP: 14096-390

E-mail: ferriolli@terra.com.br 